\title{
Short-term and long-term outcome of manipulation under anesthesia in primary frozen shoulder
}

\author{
Malay Kumar Mandal', Abhijit Sen², Anirban Paul ${ }^{3}$, Swagatam Jash ${ }^{4}$ \\ ${ }^{1}$ Assistant Professor, ${ }^{2}$ Senior Resident, ${ }^{3,4}$ Post Graduate Trainee, Department of Orthopaedics, KPC Medical College, \\ Kolkata, West Bengal, India
}

Background: Painful restriction of active and passive shoulder range of motion which cannot be attributed to any internal shoulder pathology is termed as primary frozen shoulder. It has three stages - freezing stage, frozen stage, and thawing stage. Nonsteroidal antiinflammatory drugs, physiotherapy, intra-articular corticosteroid injection, hydrodilatation, arthroscopic capsular release, and manipulation under anesthesia (MUA) are different modalities of treatment. Aims and Objectives: The main objective of our study was to assess the short-term and long-term outcome of MUA in frozen shoulder once it did not respond to 3 months course of physiotherapy. Materials and Methods: Fifty patients of primary frozen shoulder fulfilling inclusion criteria were manipulated under general anesthesia, and intra-articular Depo-Medrol and bupivacaine were administered. Functional status of the shoulder was assessed using the adjusted Constant-Murley (CM) score preoperatively and in subsequent follow-ups. Results: There was a significant improvement of mean adjusted CM score in short- and long-term follow-ups compared to pre-manipulation value. A significant negative correlation was found between the age of the patient and the final outcome. Conclusion: MUA is an effective modality of treatment in primary frozen shoulder with good short- and long-term outcomes.

Key words: Primary frozen shoulder; Manipulation under anesthesia; Short-term and longterm outcome
Access this article online

\section{Website:}

http://nepjol.info/index.php/AJMS DOI: 10.3126/ajms.v12i11.38495

E-ISSN: 2091-0576

P-ISSN: $2467-9100$

Copyright (c) 2021 Asian Journal of Medical Sciences

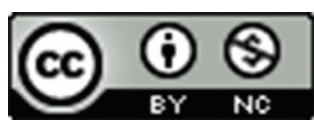

This work is licensed under a Creative Commons Attribution-NonCommercial 4.0 International License.

\section{INTRODUCTION}

Frozen shoulder is characterized by painful restriction of active as well as passive movement of the shoulder joint. When it cannot be attributed to any internal joint pathology, it is labeled as primary frozen shoulder or adhesive capsulitis, whereas passive and active restriction of shoulder movement arising out of any internal shoulder pathology like sequel of proximal humerus fracture or glenoid fracture is termed as secondary frozen shoulder. ${ }^{1,2}$ There is inflammation of joint capsule in primary frozen shoulder, which leads to thickening and adhesion of the capsule to the humeral head. ${ }^{3}$ Adhesive capsulitis can be divided into three stages - freezing stage is characterized by insidious onset of worsening pain, which is followed by frozen stage where there is established stiffness but reduced pain. In the third stage, that is, thawing stage range of motion (ROM) gradually improves with very little pain or no pain. ${ }^{4}$ Conventionally, frozen shoulder is considered to be a self-limiting disorder lasting from 18 months to 30 months. However, long-term study shows that at a mean of 7 years from the onset of symptoms, $50 \%$ of patients still complain of pain and stiffness, although only $11 \%$ have functional impairment. ${ }^{2}$ Diabetes mellitus is a common association with frozen shoulder. When frozen shoulder is associated with diabetes mellitus, it follows an intractable course..$^{5} \mathrm{~A}$ large percentage of patients respond to treatment with nonsteroidal anti-inflammatory drugs, ice packs application, and simple physiotherapy. ${ }^{6}$ Those who do not respond to this therapy are treated with either non-invasive or minimally 
invasive modalities. Manipulation under anesthesia (MUA) is a method where a patient is anesthetized with either brachial plexus block or general anesthesia and the shoulder is manipulated passively to release the adhesion and tear the shoulder joint capsule in a controlled fashion. Intra-articular injection of steroids helps suppress the inflammation of the capsule and prevent fibrosis, thus improving the ROM of the joint. ${ }^{7}$ Some surgeons prefer to do an arthroscopic release of the anterior capsule of the shoulder to treat this condition. ${ }^{8}$ Hydrodilatation is another method where the joint is distended with normal saline to rupture the joint capsule., None of the procedures is universally accepted. Proponents of MUA opine that it is an excellent procedure but critics show evidence of serious complications such as humeral shaft fracture, glenoid rim fracture, shoulder dislocation, and brachial plexus injury. ${ }^{1,10}$ With MUA, one can achieve a nearly full ROM in operation theater but as the effect of anesthesia fades, muscle tone is regained. Hence, one may not get the full ROM in early follow-ups. Manipulation causes rupture of the joint capsule which evokes inflammatory events and there is a chance of recurrence of the disease due to fibrosis. Simultaneous intra-articular injection of steroids helps suppress these events. Hence, good short-term outcome may be due to the effect of steroid. ${ }^{7}$ We want to see if this good result persists in the long run. Here, we intend to assess the short- and long-term outcomes of MUA and want to compare these two outcomes.

\section{MATERIALS AND METHODS}

This hospital-based prospective type of descriptive study was conducted in KPC Medical College and Hospital, Kolkata. Due approval was taken from the institutional ethical committee. All the patients presenting with primary frozen shoulder to the Orthopaedics Outpatient Department of KPC Medical College and Hospital and fulfilling inclusion criteria from June 2013 to September 2015 were enrolled for the study and data collection continued till September 2020. Inclusion criteria include: (1) Clinical diagnosis of idiopathic/primary frozen shoulder, (2) radiograph of the shoulder is normal, (3) age - 40-60 years, (4) patient is in frozen stage of the disease, (5) not responding to a 3 months course of physiotherapy, and (6) no history of previous manipulation/arthroscopy. Exclusion criteria include: (1) Age $<40$ years, $>60$ years, (2) secondary frozen shoulder, (3) patient is in freezing or thawing stage of the disease, and (4) less than 5 years follow-up. Baseline laboratory investigations and radiographs were recorded.

The Constant-Murley (CM) scoring system consists of four variables that are used to assess the function of the shoulder. The subjective variables are pain and activity of daily living (sleep, work, and recreation/sport) which give a total of 35 points. The objective variables are the $\mathrm{ROM}$ and strength which give a total of 65 points. Altogether, there are a total of 100 points. We excluded the objective variable "strength" because it is very difficult to assess strength in presence of pain and restricted ROM. Thus, adjusted CM score (total score 75) is derived excluding 25 points allocated for the assessment of muscle strength. Othman and Taylor ${ }^{11}$ also used similar modifications in the CM score for the assessment of shoulder function. Pre-manipulation ROM was noted and the functional status of the shoulder was assessed using adjusted CM score. Manipulation was done under general anesthesia and following specific sequence (forward elevation >abduction> external rotation [ER]) and intra-articular local anesthetic ( $10 \mathrm{ml}$ of $0.5 \%$ bupivacaine) and $80 \mathrm{mg}$ of Depo-Medrol were administered. All patients have undergone immediate post-manipulation aggressive physiotherapy. Patients were followed up at 3 weeks, 6 weeks, 3 months, 6 months, 1 year, and finally at 5 years. Results were considered unsatisfactory if forward flexion and abduction were $<120^{\circ}$ and ER score was $<4$ at 3 months. These patients were subjected to remanipulation. In every follow-up, the ROM was assessed. Adjusted CM score was assessed at follow-up at 6 weeks and at 5 years to see the short- and long-term outcomes, respectively. After collecting, data were entered into Microsoft Excel sheet and were analyzed using SPSS 25. Mean and standard deviation was used to represent continuous data. Adjusted CM score and ROM of shoulder were compared preoperatively and at different follow-ups and tested with repeated measures ANOVA. $\mathrm{P}<0.05$ was considered statistically significant.

\section{RESULTS}

From June 2013 to September 2015, a total of 57 patients were enrolled in the study, 7 patients were lost to followup. Five-year follow-up is available for the rest 50 patients. Among them, 21 patients $(42 \%)$ were male and 29 patients $(58 \%)$ were female. About $64 \%$ of patients were in the $40-50$ year age group and $36 \%$ of patients were in the 51-60 year age group. The study population has a mean age of 48.86 years, a median age of 48.00 years, and an interquartile range of $44.00-54.00$. About $90 \%$ of patients were right dominant whereas $10 \%$ of patients were left dominant. The right side was affected in $40 \%$ of cases and left in $60 \%$ of cases. About $58 \%$ of cases had symptom duration between 3 and 6 months and $42 \%$ of cases had 6 months and 1 year symptom duration (Table 1 ).

Mean pre-manipulation adjusted CM score was 27.36, mean adjusted CM score at 6 weeks follow-up was 57.00, and at 5 years follow-up was 68.40. A "repeated measures" ANOVA showed that the mean adjusted CM score differed significantly 
between time points $(\mathrm{F}[2.98]=927.18, \mathrm{P}<0.001)$. Post hoc test using Bonferroni correction revealed that adjusted $\mathrm{CM}$ score increased by an average of 29.64 from pre-manipulation level to 6 weeks $(\mathrm{P}<0.001)$ and then increased by an additional 11.40 between 6 weeks and 5 years (Table 2 and Figure 1).

Although a significant negative correlation was found between age and final outcome $(\mathrm{P}=0.04)$, actually, the association is poor (Spearman's coefficient of rank correlation [rho] -0.29 ). No significant correlation was found between gender and final outcome (point biserial correlation coefficient $[\mathrm{rPB}]+0.24$ with $\mathrm{P}=0.098)$. Pre-manipulation mean flexion was $83.10^{\circ}$ which improved during manipulation to $166.70^{\circ}$, at 3 weeks $159.70^{\circ}$, at 6 weeks $157.80^{\circ}$, at 3 months $158.80^{\circ}$, 6 months $160.80^{\circ}$, at 1 year $161.30^{\circ}$, and 5 years $163.50^{\circ}$. Abduction also improved from pre-manipulation mean of $71.10-162.80^{\circ}, 156.80^{\circ}, 156.00^{\circ}, 157.40^{\circ}, 157.10^{\circ}$, and $159.50^{\circ}$ during manipulation, 3 weeks, 6 weeks, 3 months, 6 months, 1 year, and 5 years, respectively. We also noticed an improvement in ER score from pre-manipulation mean of $3.32-8.60,7.72,7.32,7.24,7.5,7.72$, and 8.36 during manipulation, 3 weeks, 6 weeks, 3 months, 6 months, 1 year, and 5 years follow-up, respectively. Similarly, internal rotation (IR) score has shown increment from pre-manipulation mean score of 3.96-8.36 during manipulation, 7.36 at 3 weeks, 7.12 at 6 weeks, 6.80 at 3 months, 7.16 at 6 months, 7.24 at 1 year, and 7.68 at 5 years (Table 3 ).

\section{Table 1: Composition of study population}

\begin{tabular}{lcc}
\hline Variables & Sample size & Percentage \\
\hline Sex & 29 & \\
$\quad$ Male & 21 & $58 \%$ \\
$\quad$ Female & & $42 \%$ \\
Age groups (years) & 32 & \\
$\quad 40-50$ & 18 & $64 \%$ \\
$\quad 51-60$ & 45 & $36 \%$ \\
Dominance & 05 & $90 \%$ \\
$\quad$ Right & & $10 \%$ \\
$\quad$ Left & 30 & $40 \%$ \\
Side affected & & $60 \%$ \\
$\quad$ Right & 20 & \\
$\quad$ Left & & \\
\hline
\end{tabular}

\begin{tabular}{|c|c|c|c|c|}
\hline \multirow[t]{2}{*}{ Level } & \multirow[t]{2}{*}{ Mean $\pm S D$} & \multicolumn{2}{|c|}{$\begin{array}{l}95 \% \text { confidence } \\
\text { intervals }\end{array}$} & \multirow[t]{2}{*}{ F value } \\
\hline & & $\begin{array}{l}\text { Upper } \\
\text { bound }\end{array}$ & $\begin{array}{l}\text { Lower } \\
\text { bound }\end{array}$ & \\
\hline $\begin{array}{l}\text { Pre- } \\
\text { manipulation }\end{array}$ & $27.36 \pm 6.043$ & 25.643 & 29.077 & \multirow[t]{3}{*}{$\begin{array}{c}\text { Significant } \\
P<0.001\end{array}$} \\
\hline $\begin{array}{l}\text { Short term } \\
\text { (6 months) }\end{array}$ & $57.00 \pm 7.326$ & 54.918 & 59.082 & \\
\hline $\begin{array}{l}\text { Long term } \\
\text { (5 years) }\end{array}$ & $68.40 \pm 4.131$ & 67.226 & 69.574 & \\
\hline
\end{tabular}

Repeated measures ANOVA has shown that mean values of all the ROM differ significantly between time points. No significant correlation was found between the duration of symptoms and the final outcome. Three patients did not show satisfactory improvement in ROM and were subjected to remanipulation. In cases of remanipulation, repeated measures ANOVA has shown that flexion, abduction, ER score, and overall adjusted CM score varied significantly among time points after the intervention whereas the change in IR score was not significant $(\mathrm{P}>0.05)$. We did not encounter any complications such as humerus or glenoid fracture, shoulder dislocation, brachial plexus injury, or rotator cuff tear in our study.

\section{DISCUSSION}

Various treatment modalities have been described for primary frozen shoulder. However, controversy persists regarding the ideal treatment of this debilitating disorder. Most of the patients respond to conservative treatment. Those who do not respond to conservative treatment are subjected to an active intervention like MUA.

We evaluated 50 patients with frozen shoulder in our present study. In our study, mean age was 48.86 years which was comparable with the study conducted by Jenkins et al., ${ }^{12}$ where mean age was 49 years, but it differed from the mean age of the study population taken by Thomas et al., ${ }^{6}$ which was 57 years. This was because we had excluded patients above the age of 60 years to avoid the risk of iatrogenic fracture in osteoporotic bone.

We also found a significant negative correlation between age and final outcome, but the association was poor. This has not been mentioned in any other study we have gone through.

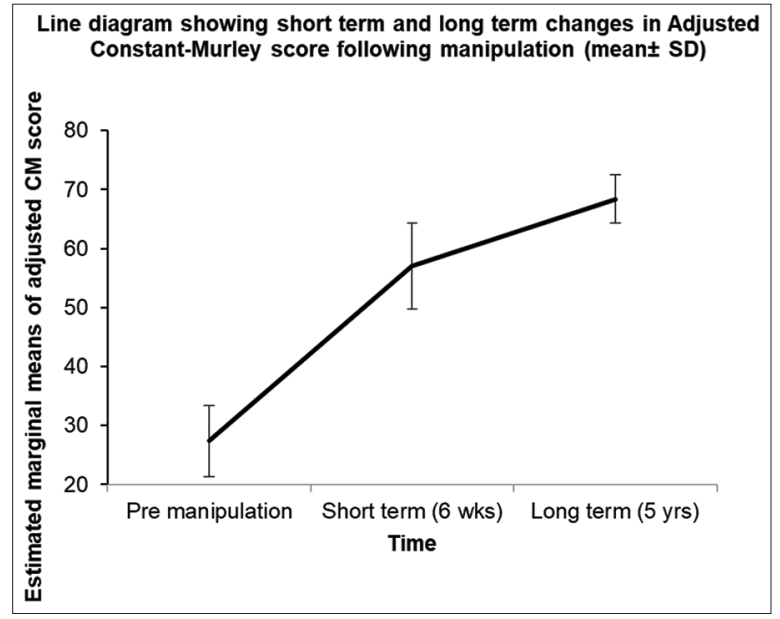

Figure 1: Short-term and long-term changes in adjusted ConstantMurley score following manipulation (mean \pm SD) 


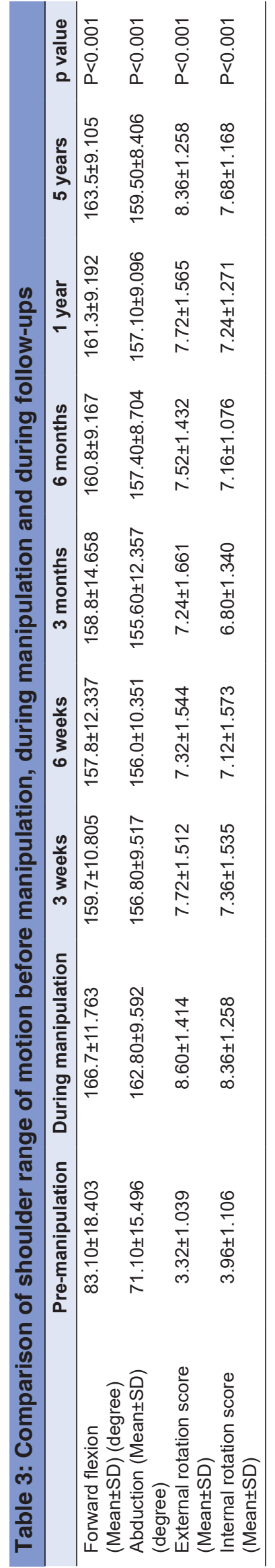

In our study population, $58 \%$ were male and $42 \%$ were female. In a study by Dodenhoff et al., $72.90 \%$ of participants were female. This dissimilarity in gender distribution is probably due to the fact that, although, in our setup, incidence of frozen shoulder was more common in females, the majority of them were reluctant to undergo any operative intervention.

Duration of symptoms and final outcome did not have any significant correlation in our study because patients were selected for manipulation only when they were in the frozen stage of the disease.

Adjusted CM score in our study was 27.36 before manipulation, 57.00 at 6 weeks, and 68.40 at 5 years. In a similar study conducted by Othman and Taylor ${ }^{11}$ which consisted of 69 study population (79 shoulders), premanipulation mean adjusted CM score was 24.70, at 6 weeks score was 54.90, and at longer follow-up the score was 72.40. Wang et al., ${ }^{5}$ studied the outcome of MUA in 63 patients with or without non-insulin-dependent diabetes mellitus and their study revealed pre-manipulation mean adjusted CM score of $22.80 \pm 4.9$, mean score of $55.78 \pm 3.46$ in non-diabetic patients, and 55.9 \pm 5.29 in diabetic patients during early follow-up, and mean score of $72.38 \pm 4.28$ in non-diabetics and $72.14 \pm 4.13$ in diabetics during long-term follow-up.

Mean pre-manipulation forward flexion of $83.10^{\circ}$ in our study can be compared with the result of the pooled analysis of data during a systematic review of literature conducted by Kraal et al., ${ }^{10}$ (pre-manipulation forward flexion of $80.40^{\circ}$ and abduction of $65.80^{\circ}$ ). In the present study, recorded mean value of forward flexion during manipulation was $166.70^{\circ}$ and at 6 weeks and 5 years follow-up, it was $157.80^{\circ}$ and $163.50^{\circ}$, respectively. Similar results were obtained by Farrell et al., ${ }^{1}$ who reported mean forward flexion of $170.00^{\circ}$ during manipulation and $168.00^{\circ}$ during long-term follow-up.

Our study population has an improvement in mean abduction from the pre-manipulation value of $71.10^{\circ}$ to short-term ( 3 weeks) value of $156.00^{\circ}$ and long-term (5 years) value of $159.50^{\circ}$. In a systematic review done by Kraal et al., ${ }^{10}$ results of pooled analysis of data regarding shoulder ROM showed a similar amount of improvement from pre-manipulation baseline value to early and late follow-up values. They calculated mean abduction of $138.30^{\circ}$ (weighted mean difference from baseline was 72.50) during short-term follow-up and $157.60^{\circ}$ (weighted mean difference from baseline was 91.80) during long-term follow-up.

In our study, IR and ER were measured based on anatomical landmarks as conventionally mentioned in the CM score chart. Mean long-term IR score was 7.68 and ER 
score was 8.36 in our study. None of the studies we have gone through has described rotation in terms of anatomical landmarks or described the individual rotation scores in their publications. Hence, it was not possible to compare our results of rotational improvement with other studies.

We did not encounter any complications in our study. Farrell et al., ${ }^{1}$ and Thomas et al., ${ }^{6}$ also noticed similar results. In our experience, if manipulation is done using proper technique and in properly selected patients, then complication is unlikely to occur.

Three patients $(6 \%)$ in our study had to undergo remanipulation. Jenkins et al., ${ }^{12}$ reported the percentage of remanipulation to be $15 \%$ in their study population, but they did not mention that how many of the patients undergoing remanipulation was having primary frozen shoulder.

We have not found any recurrence of the disease in the same shoulder during 5 years follow-up period.

Our study has some limitations such as small sample size, single-center study, and hospital bias.

\section{CONCLUSION}

From our study, it may be stated that MUA is a non-invasive, rewarding treatment modality for the management of primary frozen shoulder when it is done at the appropriate time and with proper technique. Although our study comprises a small study population, nevertheless it has been seen that this treatment modality produces good short-term as well as long-term results.

\section{REFERENCES}

1. Farrell $\mathrm{CM}$, Sperling JW and Cofield RH. Manipulation for frozen shoulder: Long-term results. J Shoulder Elbow Surg. 2005;14(5):480-484.

https://doi.org/10.1016/j.jse.2005.02.012

2. Dodenhoff RM, Levy O, Wilson A and Copeland SA. Manipulation under anesthesia for primary frozen shoulder: Effect on early recovery and return to activity. J Shoulder Elbow Surg.
2000;9(1):23-26.

https://doi.org/10.1016/S1058-2746(00)90005-3

3. Le HV, Lee SJ, Nazarian A and Rodriguez EK. Adhesive capsulitis of the shoulder: Review of pathophysiology and current clinical treatments. Shoulder Elbow. 2017;9(2):75-84.

https://doi.org/10.1177/1758573216676786

4. Manske RC and Prohaska D. Diagnosis and management of adhesive capsulitis. Curr Rev Musculoskelet Med. 2008;1(34):180-189.

https://doi.org/10.1007/s12178-008-9031-6

5. Wang JP, Huang TF, Ma HL, Hung SC, Chen TH and Liu CL. Manipulation under anaesthesia for frozen shoulder in patients with and without non-insulin dependent diabetes mellitus. Int Orthop. 2010;34(8):1227-1232.

https://doi.org/10.1007/s00264-010-0968-x

6. Thomas WJ, Jenkins EF, Owen JM, Sangster MJ, Kirubanandan R, Beynon C, et al. Treatment of frozen shoulder by manipulation under anaesthetic and injection: Does the timing of treatment affect the outcome? J Bone Joint Surg Br. 2011;93(10):1377-1381.

https://doi.org/10.1302/0301-620X.93B10.27224

7. Koh KH. Corticosteroid injection for adhesive capsulitis in primary care: A systematic review of randomised clinical trials. Singapore Med J. 2016;57(12):646-657. https://doi.org/10.11622/smedj.2016146

8. Kanbe K. Clinical outcome of arthroscopic capsular release for frozen shoulder: Essential technical points in 255 patients. J Orthop Surg Res. 2018;13(1):56. https://doi.org/10.1186/s13018-018-0758-5

9. Quraishi NA, Johnston P, Bayer, Crowe M and Chakrabarti AJ. Thawing the frozen shoulder. A randomised trial comparing manipulation under anaesthesia with hydrodilatation. J Bone Joint Surg Br. 2007;89(9):1197-1200.

https://doi.org/10.1302/0301-620X.89B9.18863

10. Kraal T, Beimers L, The B, Sierevelt I, Bekerom $M$ and Eygendaal D. Manipulation under anaesthesia for frozen shoulders: outdated technique or well-established quick fix? EFORT Open Rev. 2019;4(3):98-109. https://doi.org/10.1302/2058-5241.4.180044

11. Othman A and Taylor G. Manipulation under anaesthesia for frozen shoulder. Int Orthop. 2002;26:268-270. https://doi.org/10.1007/s00264-002-0348-2

12. Jenkins EF, Thomas WJ, Corcoran JP, Kirubanandan R, Beynon CR, Sayers AE et al. The outcome of manipulation under general anesthesia for the management of frozen shoulder in patients with diabetes mellitus. J Shoulder Elbow Surg. 2012;21(11):1492-1498.

https://doi.org/10.1016/j.jse.2011.11.006

\footnotetext{
Authors' Contributions:

MKM-Concept and design of the study, intervention, follow-up, and data collection; AS-Statistical analysis and interpretation of the result, reviewed the literature, and preparation and revision of the manuscript; AP-Interpretation of the result, review of literature, and preparation and revision of the manuscript; SJ-Review of literature and preparation of manuscript.

Work Attributed to:

KPC Medical College and Hospital, Jadavpur, Kolkata, West Bengal, India, PIN: 700032

Orcid ID:

Dr. Malay Kumar Mandal- (10) https://orcid.org/0000-0003-3101-2920

Dr. Abhijit Sen- (i) https://orcid.org/0000-0001-9962-999X

Dr. Anirban Paul- (iD https://orcid.org/0000-0002-5760-9058

Dr. Swagatam Jash- (1) https://orcid.org/0000-0003-4525-8526

Source of Funding: None, Conflict of Interest: None
} 